\title{
Noncoding RNAs, Emerging Regulators in Root Endosymbioses
}

\author{
Christine Lelandais-Brière, Jérémy Moreau, Caroline Hartmann, and Martin Crespi \\ Institute of Plant Sciences Paris-Saclay, IPS2, Univ. Paris-Diderot, CNRS, INRA, Univ. Paris-Sud, Univ. Evry, Sorbone \\ Paris-Cité, University of Paris-Saclay, 91405 Orsay, France
}

Submitted 22 October 2015. Accepted 17 December 2015.

\begin{abstract}
Endosymbiosis interactions allow plants to grow in nutrientdeficient soil environments. The arbuscular mycorrhizal (AM) symbiosis is an ancestral interaction between land plants and fungi, whereas nitrogen-fixing symbioses are highly specific for certain plants, notably major crop legumes. The signaling pathways triggered by specific lipochitooligosaccharide molecules involved in these interactions have common components that also overlap with plant root development. These pathways include receptor-like kinases, transcription factors (TFs), and various intermediate signaling effectors, including noncoding (nc)RNAs. These latter molecules have emerged as major regulators of gene expression and small ncRNAs, composed of micro (mi)RNAs and small interfering (si)RNAs, are known to control gene expression at transcriptional (chromatin) or posttranscriptional levels. In this review, we describe exciting recent data connecting variants of conserved si/miRNAs with the regulation of TFs, such as NSP2, NFY-A1, auxin-response factors, and AP2-like proteins, known to be involved in symbiosis. The link between hormonal regulations and these si- and miRNA-TF nodes is proposed in a model in which different feedback loops or regulations controlling endosymbiosis signaling are integrated. The diversity and emerging regulatory networks of young legume miRNAs are also highlighted.
\end{abstract}

Around $80 \%$ of land plants enter root symbioses with arbuscular mycorrhizal (AM) fungi. In this mutualistic interaction, nutrient transport between the two partners takes place through specialized structures inside plant root cells known as arbuscules (Strack et al. 2003). Many legumes (family Fabaceae) are also able to establish an elaborate symbiosis with nitrogen-fixing rhizobacteria (the rhizobia legume symbiosis [RLS]), characterized by the formation of specialized root organs called nodules (Martinez-Romero and Caballero-Mellado 1996; Patriarca et al. 2004). The fungal and rhizobial microsymbionts improve the mineral nutrition of host plants in exchange for photo-assimilates provided by the latter. Fungal hyphae facilitate the uptake of minerals, mainly phosphate, in mycorrhizal roots (Smith and Gianinazzi-Pearson 1988) and the nitrogenase enzyme of rhizobia fixes atmospheric nitrogen in the nodules (Thorneley 1992).

Corresponding authors: M. Crespi; E-mail: martin.crespi@u-psud.fr and C. Lelandais; E-mail: christine.lelandais@ips2-universite-paris-saclay.fr

This article is in the public domain and not copyrightable. It may be freely reprinted with customary crediting of the source. The American Phytopathological Society, 2016
Both symbiotic interactions require complex dialogues between the two partners (Gough and Cullimore 2011; Oldroyd 2013). Upon $\mathrm{N}$ or $\mathrm{P}$ starvation, plant roots exude molecules in the rhizosphere, strigolactones, recognized by AM fungi (Kretzschmar et al. 2012) and flavonoids, recognized by symbiotic rhizobia (Redmond et al. 1986). These plant signals induce the production of specific lipochitooligosaccharides (LCO), called Myc-LCOs for AM fungi and Nod factor (NF) for rhizobia, to signal the plant host (Dénarié et al. 1996; Maillet et al. 2011). Perception of these molecules by root cells triggers a signaling pathway common for the two symbioses, the common symbiotic signaling pathway (CSSP) (Oldroyd 2013). First, NF are perceived by LysM receptor-like kinases(RLK) NFR1 and NFR5 in Lotus japonicus and LYK3/4 and NFP in Medicago truncatula (Limpens et al. 2003; Madsen et al. 2003). The exact nature of Myc-LCO perception by the plant remains to be clarified (Gobbato 2015). The activated receptors interact with a receptor kinase, SYMRK for L. japonicus and DMI2 for M. truncatula (Stracke et al. 2002) to initiate a downstream signal transduction cascade involving one or more ion channel transporters (CASTOR and POLLUX in L. japonicus, DMI1 in $M$. truncatula) and three components of a nuclear pore complex (NUP85, NUP133, and NENA in L. japonicus) (Ané et al. 2004; Capoen et al. 2011). This cascade leads to calcium spiking in the nucleus, which activates a calcium calmodulindependent protein kinase (DMI3 in M. truncatula) and a nuclear protein of unknown function (CYCLOPS in L. japonicus, IPD3 in M. truncatula) (Lévy et al. 2004; Messinese et al. 2007; Yano et al. 2008). The CCSP pathway then activates a rapid reprogramming of host cell transcriptome through transcription factors (TFs) that will promote the expression of mycorrhizationor nodulation-specific (Nodulin) genes, thus allowing the establishment of the specific symbiotic structures, exchanges and interactions between the two partners (Gobbato 2015). In AMS (AM symbiosis), NODULATION SIGNALING PATHWAY2 (NSP2) together with NSP1 in epidermal cells (Takeda et al. 2013) interacts with RAM1 (REQUIRED FOR ARBUSCULAR MYCORRHIZATION-1), another GRAS TF, to promote the expression of AM-responsive genes (Gobbato et al. 2012; Rich et al. 2015; Xue et al. 2015). In RLS, the NF signaling pathway activates a set of TFs, including NSP1 and NSP2 (Hirsch et al. 2009; Oldroyd and Long 2003; Smit et al. 2005), NIN (NODULE INCEPTION) (Schauser et al. 1999, Marsh et al. 2007), subunits of the nuclear factor $\mathrm{Y}$ complex (NF-YA1 and NF-YB1) (Combier et al. 2006; Laporte et al. 2014; Soyano et al. 2013; Zanetti et al. 2010), and several members of the AP2/ERF (APETALA2-ethylene response factor) family (Middleton et al. 2007; Vernié et al. 2008). 
Given the complex reprogramming required for AMS and RLS establishment, it is not surprising that these processes are tightly regulated by a large set of hormones (e.g., auxin, cytokinin (CK), strigolactone, gibberellin, jasmonate, ethylene, abscisic acid) through complex crosstalks and in response to environmental cues (Gutjahr 2014; Ferguson and Mathesius 2014). In particular, auxin and $\mathrm{CK}$ are essential to initiate nodule formation in the root cortex (Suzaki et al. 2013). However, they may also negatively regulate nodule organogenesis in a process, called autoregulation of nodulation (AON), modulating nodule number (Ferguson and Mathesius 2014). Ethylene was reported as a negative regulator of rhizobial infection and nodule formation, partly by inhibiting polar auxin transport (Prayitno et al. 2006). Concerning AMS, strigolactones, probably together with auxin, are essential for the early steps of fungal colonization during AMS (Akiyama and Hayashi 2006; Foo 2013; Yoshida et al. 2012).

Over a period of ten years, noncoding (nc)RNAs have emerged as major regulators of gene expression in plants, playing critical roles in developmental processes, nutrient homeostasis, abiotic stress, and pathogen responses. Long ncRNAs participate in regulating transcription, splicing, RNA-directed DNA methylation, and epigenetic functions, as well as nuclear structures (Ariel et al. 2015; Chekanova 2015). Early on, ENOD40, a long nonprotein-coding RNA, was clearly associated to early nodule organogenesis in M. truncatula (Charon et al. 1999; Minami et al. 1996). The ENOD40 RNA possess a dual function, first, as RNA, by controlling the subcellular relocalization of RNA binding proteins (Campalans et al. 2004; Laporte et al. 2010) and, second, by encoding small peptides, translated as such, that seem able to bind enzymes like sucrose synthase in functional nodules (Hardin et al. 2003, Röhrig et al. 2002, 2004). Small RNAs (sRNA), composed of microRNAs (miRNAs) and small-interfering RNAs (siRNAs) in plants, repress the expression of specific target genes by base-pairing, resulting in RNA cleavage, inhibition of translation or methylation, and chromatin modification at specific loci (Vazquez et al. 2010). Around 20 miRNA families are largely conserved in the green lineage, which mainly regulate TFs involved in development and physiology (Jones-Rhoades 2012). These miRNAs generally belong to and regulate large conserved multigenic families. During evolution, the conserved miRNAs may have acquired novel functions by gene duplication and further diversification, leading to novel miRNA isoforms that may either regulate novel targets (by cleavage but also by translation inhibition), present specific spatio-temporal expression profiles, or both during root endosymbioses (Jones-Rhoades 2012). To date, more than 20 miRNAs (specific variants of conserved miRNAs or young legume-specific miRNAs) and a particular family of transacting (ta)siRNAs, called tasiARFs, have been functionally linked to root endosymbiosis. Most of them are involved in either the control of nodule or arbuscule development, nutrient signaling and homeostasis, or both (Bazin et al. 2012; Simon et al. 2009). In this minireview, we decided to focus on recent data that connected miRNAs to the NF and myc-LCO signaling pathways and hormonal regulations, in the context of the arbuscular mycorrhization (Fig. 1) and the legume-rhizobia symbiosis (Fig. 2). Finally, emerging roles of young legume-specific miRNAs through complex regulatory networks and their regulation are discussed.

\section{miR171 and NSP2: at the core of root endosymbioses.}

The conserved miRNA miR171 has been identified in all groups of Embryophyta (miRBAse database), in which it represses genes coding for GRAS proteins, a family of TFs whose members have been implicated in radial patterning in roots, gibberellin, and light signaling (Hirsch and Oldroyd 2009). In 2011, a noncanonical isoform of miR171, named mtr-miR171h, was identified in sRNA libraries of $M$. truncatula roots infected by the AM fungus Rhizophagus irregularis (Branscheid et al. 2011; Devers et al. 2011). This particular form was specific from plant species able to undergo AMS (Bazin et al. 2012). Due to a 4-nt shift in its sequence when compared with the conserved miR171 (encoded by the miR171abcdeg genes), the mtr-miR171h variant can bind to transcripts of MtNSP2 (Branscheid et al. 2011). This key GRAS TF of the CSSP is crucial for early steps of nodulation (Heckmann et al. 2006; Kaló et al. 2005; Mitra et al. 2004). In addition, it is required for correct AM fungal infection (Gobato et al. 2012; Wang et al. 2012). Indeed, in complex with another GRAS TF RAM1, NSP2 activates genes involved in cutin or strigolactone biosynthesis, two processes required for successful AM fungal infection (Liu et al. 2011; Wang et al. 2012).

The repressive role of mtr-miR171h on AMS, through NSP2 regulation, has been reported in two different studies (Hofferek et al. 2014; Lauressergues et al. 2012). Expression of mtrmiR171h increased in roots after Rhizophagus irregularis inoculation and after a treatment with purified myc-LCOs (Branscheid et al. 2011; Lauressergues et al. 2012). This induction occurred mainly in the root elongation zone and, more precisely, in its peripheral tissues (epidermis and first layers of cortex). Among the predicted targets of mtr-miR171h (MtNSP2, a NSP2-like gene, and two pentatricopeptide repeat-containing proteins), only MtNSP2 was repressed in mycorrhizal roots. In addition, PARE (parallel analysis of RNA ends), which allows the detection of miRNA cleavage products, showed that MtNSP2 transcripts were targeted by mtr-miR171h in AM-inoculated roots. Ectopic expression of mtr-miR171h in transgenic roots resulted in lower MtNSP2 RNA levels and, concomitantly, fungal colonization was reduced (Hofferek et al. 2014; Lauressergues et al. 2012), a phenotype similar to the $n s p 2$ mutant (Catoira et al. 2000). As expected, opposite phenotypes were observed in roots overexpressing a miR171-insensitive NSP2 gene, which was mutated to prevent its cleavage and regulation by miR171 (Lauressergues et al. 2012). In particular, root tips were overcolonized in comparison with control plants (45 versus 4 to $7 \%$ with the empty vector). The authors thus proposed that the myc-LCO-dependent activation of mtr-miR $171 \mathrm{~h}$ expression in peripheral tissues may help to prevent the infection of the root elongation zone by the AM fungus by inhibiting MtNSP2 and downstream gene expression in this area. This regulation may, therefore, allow the plant host to maintain root growth under AMS. Previously, miR396 and its growth-regulating factor targets were reported as regulators of AM fungus infection (Bazin et al. 2013). However, the strong repression of root growth by miR396 suggested that its impact on AM colonization was probably more associated to the reduction in root growth and development rather than to colonization per se.

The noncanonical form of miR171 is also involved in RLS. In Lotus japonicus, lja-miR171c levels increased throughout nodulation, concomitantly with the repression of LjNSP2 (De Luis et al. 2012). The use of snfl and snf2 mutants, able to form spontaneous non $\mathrm{N}_{2}$-fixing nodules in the absence of rhizobia (Tirichine et al. 2006, 2007), revealed that the activation of ljamiR $171 \mathrm{c}$ was likely associated with bacterial infection rather than nodule organogenesis per se (De Luis et al. 2012). In contrast, in M. truncatula forming indeterminate nodules with a persistent meristem, the miR171h/NSP2 regulatory node appears to control early nodule organogenesis and meristem maintenance (Ariel et al. 2012; Hofferek et al. 2014). However, in that species, functional analyses resulted in contradictory results. Indeed, Lauressergues et al. (2012) reported that ectopic expression of mtr-miR171h in transgenic roots resulted in the absence of nodulation phenotype, while Hofferek et al. (2014) observed a clear reduction in nodule density. According to these latter authors, one explanation for such opposite results may be that the 
precursor they used generated two copies of miR171h (instead of only one in the construct by Lauressergues et al. [2012]), which may compensate for the low $35 \mathrm{~S}$ promoter activity often reported in symbiotic nodules. In differentiated nodules, mtrmiR171h accumulation and MtNSP2 promoter activity overlapped in the meristematic zone, suggesting that the miRNA may also play a role later in nodulation by prohibiting MtNSP2 expression in this region, probably protecting meristematic cells from bacterial infection (Hofferek et al. 2014). However, additional functional experiments are required to confirm this hypothesis.

A detailed analysis of mtr-miR $171 \mathrm{~h}$ and MtNSP2 expression revealed that mtr-miR171h regulation depended, not only on the myc-LCO and NF pathways but, also, on the nutritional status of the plant (Hofferek et al. 2014). Indeed, mtr-miR171h levels in the absence of symbionts were higher in conditions of sufficient phosphate and low-nitrogen supply in comparison with control conditions. This miRNA may, thus, be an essential integrator of the nutritional status of the plant and endosymbioses. As phosphate and nitrate fertilization as well as mycorrhization and nodulation have been associated to increased CK levels (Barker and Tagu 2000; Ei-D et al. 1979), the authors analyzed mtr-miR $171 \mathrm{~h}$ and MtNSP2 expression profiles in the CK receptor cre1-1 (cytokinin response 1) mutant.
However, early activation of mtr-miR171h during AMS was not triggered by CK (Hofferek et al. 2014). In contrast, Ariel and colleagues (2012) showed that the miR171h/MtNSP2 node is regulated through the CK-dependent CRE1 pathway, which is necessary and sufficient to activate primordium formation (Gonzalez-Rizzo et al. 2006; Plet et al. 2011). In particular, they reported that i) activation of MtNSP2 expression by CK was directly mediated by the nodulation-responsive response regulator $1 \mathrm{TF}$, ii) $\mathrm{CK}$ activated mtr-miR171h expression, and iii) mtr-miR171h and MtNSP2 showed opposite expression patterns in response to CK. Thus, CK signaling may have a dual mode for regulating NSP2 expression in Sinorhizobium melilotiinoculated roots. It can directly activate $N S P 2$ expression but modulates a feedback control of its expression through the regulation of the mtr-miR171h specific variant.

\section{miR169 and NF-YA1: key regulators}

of meristematic activity in indeterminate nodules.

The NF-Y, also called heme-activated protein (HAP) or CCAAT-box binding factor, is an heterotrimeric TF that can recognize the CCAAT motif frequently observed in eukaryotic promoters (Mantovani 1999). NF-YB and NF-YC subunits contain a histone fold domain very similar to $\mathrm{H} 2 \mathrm{~A}$ and $\mathrm{H} 2 \mathrm{~B}$ core histone (Baxevanis et al. 1995; Zemzoumi et al. 1999) and

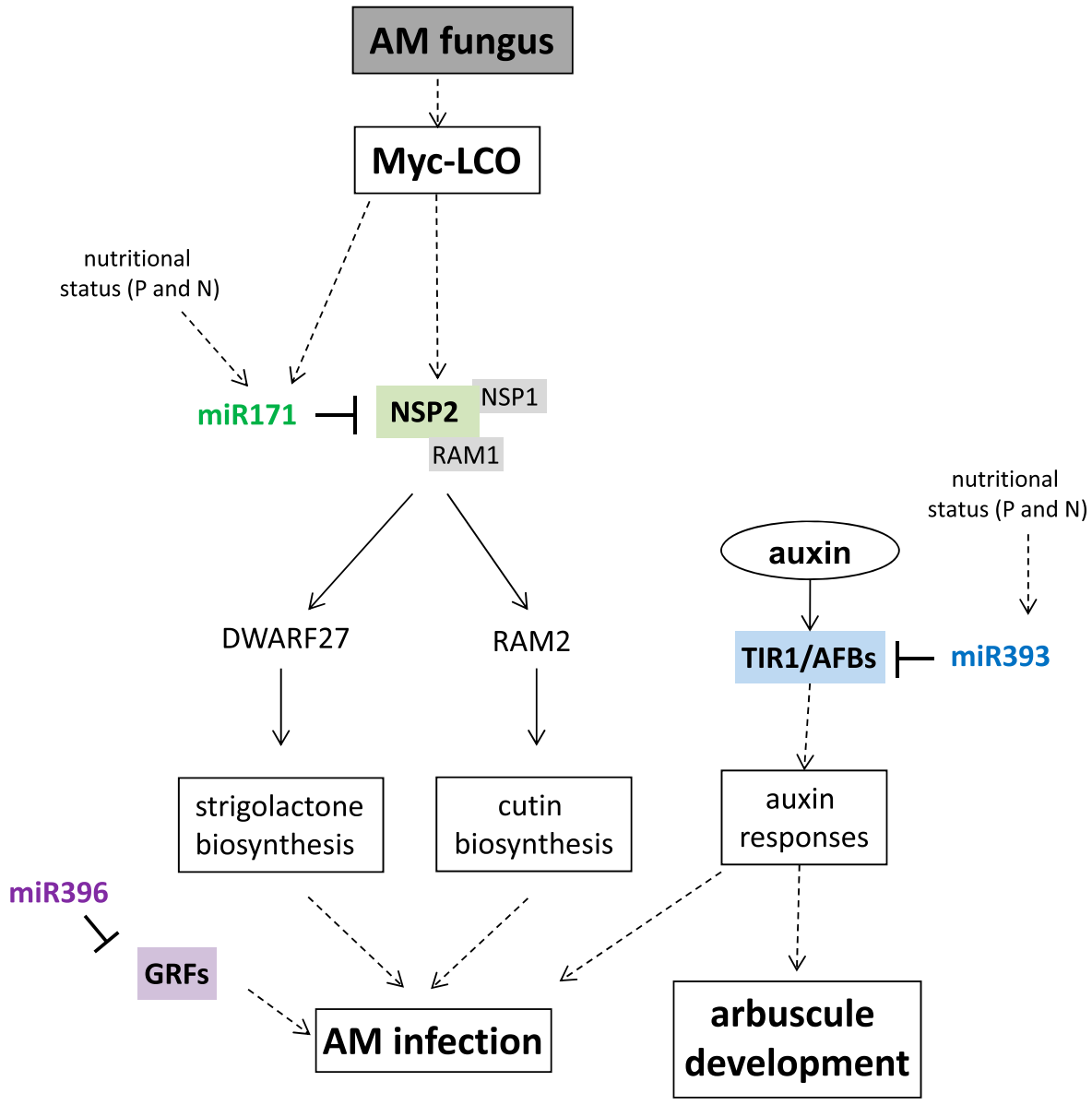

Fig. 1. Schematic representation of the interconnections between micro (mi)RNAs, myc-LCO (mycorrhizal-lipochitooligosaccharide) signaling and hormonal regulations in arbuscular mycorrhizal (AM) symbiosis. One of the key transcription factors (TFs) in the common symbiotic pathway NSP2 (NODULE SIGNALING PATHWAY 2) is regulated by a noncanonical form of miR171, repressed under phosphate starvation. NSP2 interaction with the mycorrhizationspecific RAM1 TF promotes the expression of a large set of genes, including DWARF27 and RAM2 (REQUIRED FOR ARBUSCULAR MYCORRHIZATION 2), involved in strigolactone and cutin biosynthesis, respectively, two processes that stimulate AM infection. miR396 impacts AM fungus infection through repression of growth-regulating factors (GRFs), known regulators of root development. miR393, a nitrogen and phosphate-responsive miRNA, is involved in auxin signaling homeostatis and, therefore, impacts fungal colonization and arbuscule development through repression of TRANSPORT INHIBITOR RESPONSE1/AUXIN SIGNALING F-BOX PROTEIN (TIR1/ABF) auxin receptors. Direct and indirect interactions are represented by solid or dotted lines respectively. To simplify the representation of these very complex regulatory networks, only some of the actors cited in text are present on the figure. 
the NF-YA subunit provides the DNA binding specificity (Mantovani et al. 1994). In all plant species examined so far, the three NF-Y subunits are encoded by multigenic families, thus creating, theoretically, many potential diverse complexes involved in the regulation of plant development and the response to environmental cues (Laloum et al. 2013).

Many NF-Y genes are up-regulated at infection steps and throughout RLS as well as in AMS and during the symbiosis between actinorhizal plants and Frankia bacteria (Laloum et al. 2014; Laporte et al. 2014; Soyano et al. 2013). In M. truncatula, MtNF-YA1 is one of the earliest induced TFs after $S$. meliloti inoculation. Indeed, its expression increases in the epidermis throughout bacterial infection, from the formation of microcolonies to the release of bacteria in the nodule infection zone and in cortical cells at the origin of the nodule primordia (Laporte et al. 2014). MtNF-YAl expression during these early

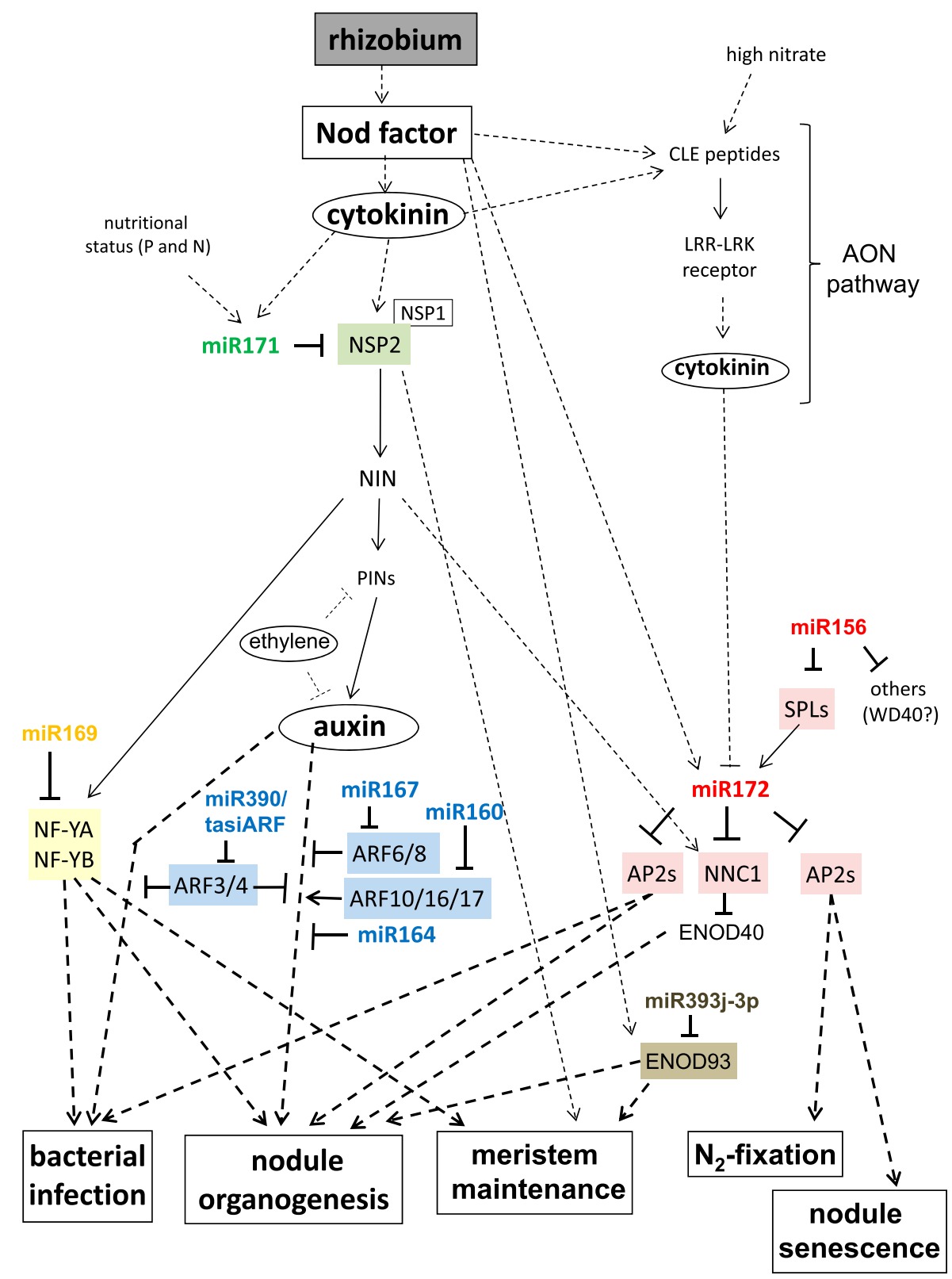

Fig. 2. Schematic representation of the interconnections between micro (mi)RNAs, Nod factor signaling, and hormonal regulations in rhizobial symbiosis. One of the key transcription factors (TFs) in the common symbiotic pathway NSP2 (NODULE SIGNALING PATHWAY 2) is regulated by a noncanonical nodulespecific form of miR171. miR169 negatively regulates NUCLEAR FACTOR $(N F)$-YA genes, TFs essential for nodule initiation and meristem maintenance. Nod factor- and cytokinin (CK)-responsive miR172 genes, combined with different AP2 (APETALA2) targets, are involved in the stimulation of rhizobial infection, nodule organogenesis, and $\mathrm{N}_{2}$ fixation and the delay of nodule senescence. miR172 may act downstream of the autoregulation of nodulation (AON) pathway, a process limiting the number of nodules formed on a plant. In this pathway, NF- or nitrate-induced CLE (clavata3/embryo surrounding region-related) peptides are perceived by leucine-rich repeat-receptor-like kinase (LRR-LRK) receptors leading to a repressive signal (including CK) for establishment of novel nodules. miR156 antagonizes miR172 action by repressing some squamosa promoter binding protein-like (SPL) TFs, which activate miR172 expression. miR393j-3p restricts nodule development through repression of the nodulin gene ENOD93. Finally, miR160 and miR167 cleave transcripts of several auxin response factors (ARFs), which are main actors of auxin responses required for nodule initiation. miR390 promotes the production of transacting small interfering (tasi)RNAs, called tasiARFs, which repress ARF3 and ARF4, two ARFs that may integrate auxin and ethylene signaling during rhizobial infection and nodule development. Direct and indirect interactions are represented by solid or dotted lines, respectively. To simplify the representation of these very complex regulatory networks, only some of the actors cited in text are present in the figure. In addition, PIN/auxin transport inhibition does not seem to be crucial for organogenesis of determinate nodules. 
nodulation steps is activated by the NF- and CK-responsive NIN TF (Laloum et al. 2014; Soyano et al. 2013) and, therefore, NF-Y complex activation relies on $\mathrm{CK}$ signaling. The involvement of $M t N F-Y A 1 / H A P 2.1$ and its paralog $M t N F-Y A 2$ in infection stages has been confirmed later by using mutants or RNAi (RNA interference) constructs (Laloum et al. 2014). NF-Y function in early nodule organogenesis may be associated to its positive action on cell cycle division genes (Soyano et al. 2013). During later stages of RLS, MtNF-YA1 is required for meristem formation and maintenance (Combier et al. 2006; Laporte et al. 2014).

The conserved miR169 has been reported to restrict NF-YA gene expression in many plant species, both by cleaving and by inhibiting the translation of the corresponding transcripts (Li et al. 2008; Sorin et al. 2014). The miR169/NF-YA regulatory node acts at the crosstalk between root development and many environmental constraints, including nitrogen or water availability ( $\mathrm{Li}$ et al. 2008; Ni et al. 2013; Sorin et al. 2014; Zhao et al. 2011). Combier et al. (2006) showed that mtr-miR169a was involved in indeterminate nodule development in M. truncatula through the repression of NF-YA1/HAP2.1. Mtr-miR169a, undetectable in roots, accumulated in young developing nodules and reached maximal levels in 10-day-old functional nodules. In mature nodules, this variant was expressed in the infection zone adjacent to the apical meristem, while its $M t N F-Y A 1$ target was restricted to the meristem. Despite the known roles of $N F-Y A 1$ at early stages of RLS, mtr-miR169a overexpression as well as silencing of $N F-Y A l$ but also ectopic expression of a miR169-insensitive $N F-Y A 1$ gene did not result in significant defects in rhizobial infection and nodule numbers. However, round-shaped nodules with no functional meristem were observed, indicating that a fine-tuned regulation of MtNF-YAl expression by miR169 was required for meristem function and persistence. Also, Reynoso et al. (2013) showed that miR169 was strongly underrepresented in polysomal fractions of S.meliloti roots $48 \mathrm{~h}$ postinoculation with S. meliloti, concomitant with an increased accumulation of NF-YAl, suggesting that, in addition to mRNA cleavage, miR169 might contribute to the translational repression of NFY-Al before but not during infection.

\section{miR172 regulates rhizobial symbiosis through repression of different APETALA2 TFs.}

miR172 and miR156 play antagonist roles in plant developmental transitions ( $\mathrm{Li}$ and Zhang 2016; Rubio-Somoza and Weigel 2011), such as developmental timing, flowering processes, juvenile-to-adult phase transition, and lateral root organogenesis ( $\mathrm{Yu}$ et al. 2015). In all species, miR172 was shown to repress conserved members of the large family of AP2 TFs (Aukerman and Sakai 2003; Huijser and Schmid 2011). In turn, miR156 controls a subset of conserved squamosa promoter binding protein-like (SPL) TFs, which directly interact with the promoters of miR172 genes to activate their expression (Wu et al. 2009). In legumes, these two miRNAs are encoded by multigenic families, with four to 12 members for miR172 and 10 and 28 genes for miR156 (miRBAse) (Holt et al. 2015; Nova-Franco et al. 2015; Wang et al. 2015b). There are five, six, and $10 A P 2$ genes with predicted miR172-binding sites in L. japonicus, Phaseolus vulgaris, and soybean, respectively (Nova-Franco et al. 2015; Holt et al. 2015; Song et al. 2011). In addition to the expected SPL TFs, novel miR156 targets, such as a WD40-like protein, were identified in M. truncatula and soybean, suggesting a putative specialization in legumes (Naya et al. 2010; Wang et al. 2015b).

During the last two years, it became evident that miR172 and miR156 are positive and negative players in rhizobial-legume symbiosis, respectively, and control different aspects of this process (rhizobial infection, nodule organogenesis, efficiency of $\mathrm{N}_{2}$-fixation). Ectopic expression of nodulation-responsive miR172 genes in soybean and common bean resulted in increased root-hair deformation and numbers of infection events (Nova-Franco et al. 2015; Wang et al. 2014) but not in L. japonicus (Holt et al. 2015), suggesting species-specific effects. In contrast, in all legumes tested, the mir156/miR172 pair controls both nodule numbers and atmospheric nitrogenfixation efficiency. In soybean, Yan et al. (2013) first reported that miR172 levels were higher in functional nodules (20 days postinoculation [dpi]) in comparison with young developing (10-dpi) or senescent (30-dpi) ones. Ectopic expression of gmamiR $172 \mathrm{j}$ in roots, using a strong ectopic Cassava mosaic virus (CvMV) promoter, led to an increased number of mature nodules, with higher $\mathrm{N}_{2}$-fixation efficiency. Among the three $A P 2$ predicted targets (GmAP2-1 to GmAP2-3) that were downregulated in CvMV::miR172 roots, only GmAP2-2 was correlated to the efficiency of nodulation (Yan et al. 2013). In 2014, Wang and colleagues reported that the nodulation-responsive gma-miR172c gene controlled nodule formation through the repression of another AP2 gene, called GmNNC1 (NODULE NUMBER CONTROL 1). Between 3 and 7 dpi with Bradyrhizobium japonicum, gma-miR172c expression occurred mainly in cortical dividing cells and developing nodule primordia. In mature nodules, it was detected in both infection and nitrogenfixation zones. When gma-miR172c was ectopically expressed in roots, higher numbers of primordia and mature nodules were formed. In turn, transgenic roots inactivated for miR172 (using a mimicry construct preventing the binding of miR172 to its target) showed the opposite phenotype. Following PARE, transcript cleavage of three $A P 2$ genes, including GmAP2-2 and $G m N N C 1$, was confirmed in nodulated roots. GmNNC1RNAi roots developed more primordia and mature nodules while overexpression of a mir172-resistant form of this gene significantly reduced nodule formation compared with controls. In $P$. vulgaris, also, ectopic expression of the nodulation-responsive pvu-miR172c gene resulted in more abundant nodules with higher fixation efficiency, at least through the repression of a $P v A P 2.1$ gene (Nova-Franco et al. 2015). Altogether, these results showed that miR172 promotes nodule organogenesis via the posttranscriptional regulation of different $A P 2$ TFs. In addition, the antagonist role of miR156 in the control of nodule number and rhizobial infection was confirmed in soybean and Lotus spp. (Wang et al. 2015a; Yan et al. 2013).

The expression of the nodulation-responsive miR172 variants is dependent on NF signaling (Holt et al. 2015; NovaFranco et al. 2015; Wang et al. 2014, 2015b). In soybean, for instance, activation of gma-miR172c after B. japonicum inoculation was dependent on NF perception by both NFR5 and NFR1 receptors (Wang et al. 2014). Transcript levels of the early nodulins GmNIN and GmENOD40 were positively correlated to the abundance and activity of gma-miR172c, suggesting that GmNNC1 (or another target of this miRNA) may repress their expression. The direct interaction between GmNNC1 and the NIN or ENOD4O promoters was thus tested, thanks to a large set of approaches. Altogether, these experiments showed that NNC1 was able to restrict the transcription of the two GmENOD40 genes through direct interaction with their promoters, while no direct binding could be established with the GmNIN promoter. The authors, thus, proposed that, in the presence of rhizobium (and, more precisely, NF), gmamiR172c expression was induced through the NF pathway, leading to repression of $G m N N C 1$ and further activation of GmENOD40 genes, thus promoting early nodule organogenesis.

Additional data indicated that miR172/AP2 node may act downstream of the AON pathway, which limits the number of nodules formed on a plant. This pathway relies on a systemic 
long-distance signaling between roots and shoots. Rhizobiainduced CLE peptides are transported from roots to shoots and perceived by leucine-rich repeat (LRR)-RLK receptors, while in turn, a nodulation-repressive signal (composed at least of $\mathrm{CK}$ ) is transported in the opposite direction to prevent a continued nodule development. The increased nodule density in roots overexpressing miR172 suggested that this miRNA might also be associated to the AON pathway. For that, Wang et al. (2014) used a soybean hypernodulating mutant, nts1116, defective in AON regulation, which carries a missense mutation in NARK (nodulation autoregulation receptor kinase), the CLE peptide receptor in soybean (Searle et al. 2003). First, gmamiR172c expression at 5 and 10 dpi with B. japonicum was higher in the mutant compared with the wild type. Second, its overexpression exacerbated the hypernodulating phenotype of the nts1116 mutant, whereas its inactivation significantly reduced the total number of nodules. In conclusion, gma-mir172c expression may be negatively regulated by the AON pathway and high levels of miR172c in the nark mutant may explain, at least partially, its hypernodulating phenotype.

Local high nitrate or ammonium contents are detrimental for nodule initiation and function (Barbulova et al. 2007; Mortier et al. 2012). This repressive effect of nitrogen compounds acts locally on nodule initiation and systemically on $\mathrm{N}_{2}$-fixation activity of mature nodules (Caetano-Anollés and Gresshoff 1991; Cho and Harper 1991). In P. vulgaris, Nova-Franco et al. (2015) reported that pvu-miR172c levels were inversely correlated to nodule functionality, whereas one of its predicted targets $P v A P 2.1$ showed an opposite profile. Moreover, plants with ectopic pvu-miR172c expression were less sensitive to nodulation inhibition by nitrates than the wild-type plants. According to these authors, the decrease of miR172c levels at the onset of nodule senescence may allow $P v A P 2-1$ to activate the expression of several senescence-related protein kinases.

\section{Several miRNAs are guardians of auxin signaling homeostasis during root endosymbioses.}

Both AMS and RLS are under the control of auxin regulation. Changes in auxin contents in AM-inoculated roots and increases in AM colonization in roots treated with auxin or auxin transport inhibitors have been reported (Gutjahr 2014). In addition, pea and tomato mutants with defects in auxin responses exhibit reduced levels of AM colonization whereas arbuscule morphology remained unchanged. These infection phenotypes have been correlated to a lower strigolactone biosynthesis, probably due to enhanced auxin signaling (Foo 2013; Hanlon and Coenen 2011). Auxin also orchestrates different stages of nodule development. In particular, together with CK, this hormone is essential for nodule initiation, when root cortical cells de-differentiate and start to divide to produce the nodule primordium (Ferguson and Mathesius 2014). Use of auxin-responsive reporter genes (GH3:GUS or DR5:GUS or $G F P$ ) indicated that local auxin accumulation as well as enhanced auxin responses occurred at sites of nodule initiation (Mathesius et al. 1998; Pacios-Bras et al. 2003; Suzaki et al. 2012). In addition, analyses of the cre 1 mutant ( $\mathrm{Ng}$ et al. 2015; Plet et al. 2011) revealed that these modifications were under the positive regulation of CK signaling at least in $M$. truncatula.

Basically, in the presence of auxin, F-box proteins (TIR1/AFB) of the SCF ${ }^{\mathrm{TIR} 1 / \mathrm{AFB}}$ complex, interact with auxin and indole-3-acetic acid (AUX/IAA) proteins and direct their degradation through the proteasome. As AUX/IAAs are repressors of the ARF TFs, their degradation allows ARFs to regulate the myriad of auxin response genes. Again, AUX/IAA and ARF proteins are encoded by multigenic families (Guilfoyle and Hagen 2007; Overvoorde et al. 2005). However, although genetic studies suggest considerable functional redundancy within these families (Okushima et al. 2005; Overvoorde et al. 2005), the fact that arf mutants have specific developmental defects clearly indicates some functional specialization. During these last years, several mi/siRNAs, which repress key components of auxin signaling, have been characterized with respect to their roles in root endosymbioses.

Although its real link with auxin signaling remains to be clarified, miR164 was the first 'auxin-related' miRNA associated to nodulation (D'haeseleer et al. 2011). In Arabidopsis thaliana, this conserved miRNA represses AtNAC1, an auxin-responsive $\mathrm{TF}$ that promotes lateral root development (Xie et al. 2000). In M. truncatula, expression levels of MtNAC1, the closest AtNAC1 homolog, increased at 8 and 12 dpi with $S$. meliloti and, then, decreased in differentiated nodules. Although MtNACl RNAi or overexpression had no obvious effect on RLS, ectopic expression of mtr-miR164 resulted in a reduced number of nodules in $M$. truncatula. On the other hand, overexpression of gma-miR164 did not significantly affect nodulation in soybean, forming determinate nodules (Mao et al. 2013). Thus, miR164 may regulate indeterminate nodule formation through other targets than MtNACl in M. truncatula (D'haeseleer et al. 2011).

The conserved miRNA miR393 regulates members of the auxin receptor TIR1/AFB gene family (Parry et al. 2009; SiAmmour et al. 2011; Vidal et al. 2010) and is essential for auxin signaling homeostasis during development and in response to environment cues (Vidal et al. 2010; Windels et al. 2014). Recently, its role in endomycorrhization was characterized (Etemadi et al. 2014). In rice, tomato, and the model legume M. truncatula, miR393 expression decreases in roots inoculated with AM fungi, independently of the myc-LCO signal. Ectopic expression of miR393 in roots resulted in the downregulation of $T I R 1 / A F B$ targets and a reduced sensitivity to auxin and caused a developmental arrest of arbuscules in many infected cortical cells (Etemadi et al. 2014). These unexpected results indicated that miR393 and the TIR1/AFB-dependent auxin signaling may be required for arbuscule formation more than colonization per se. Ectopic expression of miR393 in legumes also resulted in auxin hyposensitivity. However, in soybean (forming determinate nodules), this reduced auxin sensitivity did not influence the number of nodules per root (Turner et al. 2013), while a reduced number of nodules was observed in $M$. truncatula (Mao et al. 2013). It was suggested that the formation of indeterminate nodules may require a higher but narrow window of auxin sensitivity (regulated by miR393) than determinate ones. Finally, in soybean, Yan et al. (2015a) recently showed that, unlike miR393j, miR393j-3p-the miRNA produced from the other strand of the miR393j precursor or miR393j*-was up-regulated during nodulation. According to PARE, it was able to posttranscriptionally repress the expression of ENOD93, a nodule-specific gene with unknown function (Kouchi and Hata 1993). Roots with enhanced levels of miR393j-3p or specifically silenced for ENOD93 showed a reduced number of mature nodules (Yan et al. 2015a). Accordingly, ENOD93 expression in the meristem of young nodules and in infected cells of mature ones suggested that miR393j-3p may control meristematic activity and maintenance, during the early stages of nodule development, through ENOD93 repression. Hence, the miR393j isoform may have gained an essential role in nodulation, independent of auxin, through its specific miRNA*.

Finally, three conserved miRNAs trigger repression of different ARFs. miR160 and miR167 directly bind to ARF10, $A R F 16$, and $A R F 17$ and $A R F 6$ and $A R F 8$ mRNAs, respectively. miR390 indirectly represses ARF2, ARF3, and ARF4. Once loaded in an RNA-induced silencing complex containing an AGO7 protein, this miRNA cleaves the TAS3 long noncoding RNAs. The resulting cleavage products, after conversion into 
long double-stranded (ds)RNAs by the RNA-dependent RNA polymerase 6 (RDR6) together with its partner SGS3 (suppressor of gene silencing 3), are processed into several phased secondary siRNAs through Dicer-like 4 (DCL4) activity. Some of these TAS3-derived tasiRNAs, called tasiARFs, specifically bind to $A R F 2, A R F 3$, and $A R F 4$ mRNAs, resulting in their posttranscriptional degradation. According their roles in auxin responses, miR160, miR167, and miR390 are key regulators of various developmental steps, including lateral root formation (Khan et al. 2012), and recently, several lines of evidence highlighted their involvement in RLS.

miR167 and miR160 have opposite roles in nodule organogenesis (Turner et al. 2013). Overexpression of miR160 resulted in lower MtARF10, MtARF16, and MtARF17 mRNA levels and restricted both root growth and nodule numbers in M. truncatula (Bustos-Sanmamed et al. 2013). Likewise, soybean roots with ectopic expression of gma-miR160a, hypersensitive to auxin, formed fewer nodule primordia. Interestingly, similar phenotypes were obtained when gma-miR160a expression was driven by a GmENOD 40 promoter and was, thus, specifically activated at sites of early nodule organogenesis (Turner et al. 2013). In addition, the numbers of emerging and mature nodules were more severely impaired, indicating that miR160 controlled not only the initiation of both determinate and indeterminate nodules but, also, later stages of development. Wang et al. (2015a) reported that gma-miR167c expression was induced both by auxin and by the NF pathway in soybean. Ectopic expression of this miRNA as well as RNAi of its GmARF8 target led to lower auxin sensitivity associated to stimulated lateral root and nodule formation. As expected, miR167 inactivation resulted in opposite phenotypes (Wang et al. 2015a). Both studies suggested a feedback regulatory loop between miR160- and miR167-dependent auxin responses and the NF pathway to regulate nodule initiation in soybean. Indeed, miR160-overexpressing roots, hypersensitive to auxin, were less sensitive to CK and showed lower expression of the NF(and CK)-responsive genes $N I N, N S P 1$, and $N F Y$ - $A$ in response to rhizobial infection. In turn, miR167 ectopic expression resulted in auxin hyposensitivity and enhanced expression of the latter genes. Altogether, these results indicate that the feedback loops between auxin responses and the NF pathway may occur upstream of these symbiotically related genes.

Indirect evidences for the control of nodule formation by miR390 and tasiARFs came from the characterization of mutants affected in tasiRNA biogenesis (rell and rel3 mutant affected in SGS3 and AGO7 activity, respectively, in L. japonicus [Li et al. 2014; Yan et al. 2010], sgs3 and rdr6 mutants in M. truncatula [Bustos-Sanmamed et al. 2014]). In addition to strong pleiotropic developmental defects, the Lotus rell and rel3 mutant as well as three of the four $s g s 3$ or $r d r 6$ mutants in $M$. truncatula displayed functional nodules but in lower abundance as well as reduced root growth and lateral root density. These phenotypes may be the consequence of altered auxin responses due to reduced levels of tasiARFs. However, other secondary phased siRNAs (phasiRNA) depending on RDR6/SGS3 and that follow the same biogenesis pathway than tasiRNAs may also be involved in these strong phenotypes. In particular, large sets of secondary phasiRNAs are produced from and repress nucleotide binding site (NBS)-LRR disease resistance genes that may control the efficiency of RLS in modulating plant defenses (Arikit et al. 2014; BustosSanmamed et al. 2014; Zhai et al. 2011). For instance, overexpression of the nodulation-responsive miR482, one miRNA triggering phasiRNA production from NBS-LRR genes, was reported to promote soybean nodulation ( $\mathrm{Li}$ et al. 2010). However, Bustos-Sanmamed et al. (2014) characterized a hypomorphic $r d r 6$ mutant in which accumulation of 433 different
phasiRNAs was impaired but tasiARF levels remained similar to the wild-type plants. Given that this mutant had no obvious defect in RLS, we assume that the low-nodulation phenotypes observed in the rel as well as the additional sgs3 and rdr6 mutants were mainly associated to the down-accumulation of tasiARFs and the subsequent overexpression of their ARF3 and ARF4 targets rather than the depletion of NBS-related phasiRNAs. The impaired nodulation of the rel3 and rell mutants was correlated with defects in rhizobial infection efficiency, nodule initiation, and emergence ( $\mathrm{Li}$ et al. 2014). In addition, the inhibition of nodulation by NPA (an auxin transport inhibitor) in rel3 was weakened by aminoethoxyvinylglycine treatment, an inhibitor of ethylene synthesis, showing that the effect of the auxin transport inhibitor on nodulation in rel3 was dependent on changes in ethylene contents. The miR390/tasiARF/ARF3,ARF4 regulatory node may, thus, serve to integrate auxin and ethylene signaling during nodulation.

\section{Exploring novel miRNA functions in root endosymbioses.}

Previous examples described in this review illustrated how miRNAs conserved in most plant species have acquired regulatory functions in root endosymbioses, i.e., by the generation of novel miRNA variants or miRNA* (to conserved miRNAs) that recognize new targets or display particular expression profiles. However, beyond these highly conserved miRNAs, a large diversity of miRNAs arose recently and are lineage- or species-specific. These young miRNAs may regulate specific traits and be crucial players in local adaptation and interactions with the environment. In legumes, next-generation DNA sequencing allowed discovery of several hundreds of different miRNAs and siRNAs, including legume-specific ones (M. truncatula: Devers et al. 2011; Formey et al. 2014; Jagadeeswaran et al. 2009; Lelandais-Brière et al. 2009; Szittya et al. 2008; Zhai et al. 2011; soybean: Kulcheski et al. 2010; Arikit et al. 2014; Goettel et al. 2014; Subramanian et al. 2008; Wang et al. 2009; Zhai et al. 2011; Lotus japonicus: De Luis et al. 2012; P. vulgaris: Formey et al. 2015; chickpea: Jain et al. 2014; Kohli et al. 2014; peanut: Zhao et al. 2010). For M. truncatula and soybean, respectively, 242 and 238 novel miRNA families are listed in miRBase (v21, updated in August 2014). In addition, large sets of transcripts cleaved by miRNAs and siRNAs have been identified through PARE in M. truncatula (Devers et al. 2011; Zhai et al. 2011), soybean (Yan et al. 2015a and b; Zhai et al. 2011) and P. vulgaris (Formey et al. 2015). For instance, in M. truncatula, Devers et al. (2011) first identified 243 miRNAs, including 100 novel candidates able to cleave 185 different mRNAs in nonmycorrhizal and mycorrhizal roots. Analyses of 22 sRNA libraries from roots under different biotic interactions (fungal or bacterial pathogens and symbionts) or treated with NF and myc-LCO factors allowed description of a total of 365 miRNA families, including 44 specific to legumes (Formey et al. 2014). Thanks to triplicate libraries for each condition, differential accumulation in response to either NF, Myc factor, or both treatments was observed for 32 conserved and 30 novel miRNAs, suggesting complex miRNA-dependent regulations in response to the symbiotic signals. In addition, the novel young miRNAs appeared to be mainly responsive to one particular biotic interaction, again highlighting their putative involvement in specific local adaptation to a biotic interaction. Among the 430 targets validated by PARE, mRNAs targeted by novel miRNAs showed more diverse functions (e.g., enzymes, protein binding) than conserved ones (mainly TFs). A weighted gene coexpression network analysis revealed relevant coregulatory modules during nodulation and in response to $\mathrm{NF}$ treatment. Coregulation of conserved miRNAs, already involved in symbioses - such as miR169 variants, miR171h, or miR393with some newly discovered miRNAs and some of their predicted 
targets will certainly be helpful to select novel miRNAs for functional analyses.

In soybean, 35 novel miRNAs were first identified in sRNA libraries from roots treated with B. japonicum (Subramanian et al. 2008). Among them, overexpression of two legumespecific miRNAs, miR1512 and miR1515, increased the number of nodules ( $\mathrm{Li}$ et al. 2010). miR1512 and its target, a copine-like calmodulin-binding gene, may be involved in cell signaling and membrane trafficking during nodulation (Li et al. 2010). According to rapid amplification of cDNA ends polymerase chain reaction experiments, $\mathrm{miR} 1515$ is able to cleave a DCL2-like gene in B. japonicum-inoculated roots. In other species, DCL2 serves as a major regulator of dsRNA processing, primarily in viral defense responses but also in the biogenesis of 22-nt miRNAs, able to initiate transitive silencing (Parent et al. 2015). Although additional functional analyses are required, it is tempting to speculate that miR1515 may regulate DCL2-mediated pathways during nodulation. More recently, deep sequencing of sRNA libraries from nodules, at five developmental stages (again in triplicate), revealed the differential accumulation of 139 miRNAs, regulating a total of 533 targets (including the ENOD93 target of miR393j-3p [Yan et al. 2015a]). To identify infection-responsive miRNAs, Yan et al. (2015b) constructed sRNA libraries from root hairs infected or not with $B$. japonicum. Sequencing of these libraries (also performed in triplicate) identified a total of 114 miRNAs with 405 miRNA targets. Among $48 \mathrm{~B}$. japonicum-responsive miRNAs, two legume- (gma-miR2606b and miR1514) and two soybean-specific (TAG_2383310 and gma-miR4416) candidates were selected for additional analyses. Overexpression of miR2606 increased significantly the number of nodules formed on transgenic roots and resulted in lower levels of its mannosyloligosaccharide 1, 2-alpha-mannosidase target mRNA coding for an enzyme probably involved in $\mathrm{N}$-glycan processing and cell-wall structure (Liebminger et al. 2009). Roots overexpressing gma-miR4416 showed a clear repression of a peroxidase gene similar to RIP1 (rhizobium-induced peroxidase 1 ), an early nodulin induced in root hairs during the preinfection stage in M. truncatula (Cook et al. 1995). The concomitant reduction of nodule number strongly suggested that gma-miR4416 may control rhizobial infection by regulating antioxidant reactions in root hairs (Yan et al. 2015b). These two examples clearly reveal that study of novel miRNAs in legumes may help to discover novel mechanisms controlling nodulation.

In conclusion, in recent years, several conserved miRNAs emerged as key regulators of either the NF/myc-LCO signaling pathways, hormonal regulations, or both in both AMS and RLS. Their direct targets, mainly TFs, were identified but downstream regulations generally remain to be investigated. In addition, a plethora of novel endosymbiosis-responsive miRNAs has been identified in legumes, revealing very complex regulatory networks and new miRNA functions in plant-microbe interactions. Finally, identification and functional analyses of long ncRNAs and siRNAs, in particular the NBS-LRR-originating phasiRNAs and heterochromatic siRNAs linked to epigenetic regulations, will probably highlight novel regulatory mechanisms acting in root endosymbioses.

\section{LITERATURE CITED}

Akiyama, K., and Hayashi, H. 2006. Strigolactones: Chemical signals for fungal symbionts and parasitic weeds in plant roots. Ann. Bot. (Lond.) 97:925-931.

Ané, J. M., Kiss, G. B., Riely, B. K., Penmetsa, R. V., Oldroyd, G. E., Ayax, C., Lévy, J., Debellé, F., Baek, J. M., Kalo, P., Rosenberg, C., Roe, B. A., Long, S. R., Dénarié, J., and Cook, D. R. 2004. Medicago truncatula DMI1 required for bacterial and fungal symbioses in legumes. Science 303:1364-1367.
Ariel, F., Brault-Hernandez, M., Laffont, C., Huault, E., Brault, M., Plet, J., Moison, M., Blanchet, S., Ichanté, J. L., Chabaud, M., Carrere, S., Crespi, M., Chan, R. L., and Frugier, F. 2012. Two direct targets of cytokinin signaling regulate symbiotic nodulation in Medicago truncatula. Plant Cell 24:3838-3852.

Ariel, F., Romero-Barrios, N., Jégu, T., Benhamed, M., and Crespi, M. 2015. Battles and hijacks: Noncoding transcription in plants. Trends Plant Sci. 20:362-371.

Arikit, S., Xia, R., Kakrana, A., Huang, K., Zhai, J., Yan, Z., Valdés-López, O., Prince, S., Musket, T. A., Nguyen, H. T., Stacey, G., and Meyers, B. C. 2014. An atlas of soybean small RNAs identifies phased siRNAs from hundreds of coding genes. Plant Cell 26:4584-4601.

Aukerman, M. J., and Sakai, H. 2003. Regulation of flowering time and floral organ identity by a microRNA and its APETALA2-like target genes. Plant Cell 15:2730-2741.

Barbulova, A., Rogato, A., D’Apuzzo, E., Omrane, S., and Chiurazzi, M. 2007. Differential effects of combined N sources on early steps of the Nod factor-dependent transduction pathway in Lotus japonicus. Mol. Plant-Microbe Interact 20:994-1003.

Barker, S. J., and Tagu, D. 2000. The roles of auxins and cytokinins in mycorrhizal symbioses. J. Plant Growth Regul. 19:144-154.

Baxevanis, A. D., Arents, G., Moudrianakis, E. N., and Landsman, D. 1995. A variety of DNA-binding and multimeric proteins contain the histone fold motif. Nucleic Acids Res. 23:2685-2691.

Bazin, J., Bustos-Sanmamed, P., Hartmann, C., Lelandais-Brière, C., and Crespi, M. 2012. Complexity of miRNA-dependent regulation in root symbiosis. Philos. Trans. R. Soc. Lond. B Biol. Sci. 367:1570-1579.

Bazin, J., Khan, G. A., Combier, J. P., Bustos-Sanmamed, P., Debernardi, J. M., Rodriguez, R., Sorin, C., Palatnik, J., Hartmann, C., Crespi, M., and Lelandais-Brière, C. 2013. miR396 affects mycorrhization and root meristem activity in the legume Medicago truncatula. Plant J. 74:920-934.

Branscheid, A., Devers, E. A., May, P., and Krajinski, F. 2011. Distribution pattern of small RNA and degradome reads provides information on miRNA gene structure and regulation. Plant Signal. Behav. 6:1609-1611.

Bustos-Sanmamed, P., Mao, G., Deng, Y., Elouet, M., Khan, G. A., Bazin, J., Turner, M., Subramanian, S., Yu, O., Crespi, M., and LelandaisBrière, C. 2013. miR160 overexpression affects root growth and nitrogen-fixing nodule number in Medicago truncatula. Funct. Plant Biol. 40:1208-1220.

Bustos-Sanmamed, P., Hudik, E., Laffont, C., Reynes, C., Sallet, E., Wen, J., Mysore, K. S., Camproux, A. C., Hartmann, C., Gouzy, J., Frugier, F., Crespi, M., and Lelandais-Brière, C. 2014. A Medicago truncatula rdr6 allele impairs transgene silencing and endogenous phased siRNA production but not development. Plant Biotechnol. J. 12:1308-1318.

Caetano-Anollés, G., and Gresshoff, P. M. 1991. Efficiency of nodule initiation and autoregulatory responses in a supernodulating soybean mutant. Appl. Environ. Microbiol. 57:2205-2210.

Campalans, A., Kondorosi, A., and Crespi, M. 2004. Enod40, a short open reading frame-containing mRNA, induces cytoplasmic localization of a nuclear RNA binding protein in Medicago truncatula. Plant Cell 16: 1047-1059.

Capoen, W., Sun, J., Wysham, D., Otegui, M. S., Venkateshwaran, M., Hirsch, S., Miwa, H., Downie, J. A., Morris, R. J., Ané, J. M., and Oldroyd, G. E. 2011. Nuclear membranes control symbiotic calcium signaling of legumes. Proc. Natl. Acad. Sci. U.S.A. 108:14348-14353.

Catoira, R., Galera, C., de Billy, F., Penmetsa, R. V., Journet, E. P., Maillet, F., Rosenberg, C., Cook, D., Gough, C., and Dénarié, J. 2000. Four genes of Medicago truncatula controlling components of a nod factor transduction pathway. Plant Cell 12:1647-1666.

Charon, C., Sousa, C., Crespi, M., and Kondorosi, A. 1999. Alteration of Enod40 expression modifies Medicago truncatula root nodule development induced by sinorhizobium meliloti. Plant Cell 11:1953-1966.

Chekanova, J. A. 2015. Long non-coding RNAs and their functions in plants. Curr. Opin. Plant Biol. 27:207-216.

Cho, M. J., and Harper, J. E. 1991. Effect of localized nitrate application on isoflavonoid concentration and nodulation in split-root systems of wildtype and nodulation-mutant soybean plants. Plant Physiol. 95:11061112.

Combier, J. P., Frugier, F., de Billy, F., Boualem, A., El-Yahyaoui, F., Moreau, S., Vernié, T., Ott, T., Gamas, P., Crespi, M., and Niebel, A. 2006. MtHAP2-1 is a key transcriptional regulator of symbiotic nodule development regulated by microRNA169 in Medicago truncatula. Genes Dev. 20:3084-3088.

Cook, D., Dreyer, D., Bonnet, D., Howell, M., Nony, E., and VandenBosch, K. 1995. Transient induction of a peroxidase gene in Medicago truncatula precedes infection by Rhizobium meliloti. Plant Cell 7:43-55.

De Luis, A., Markmann, K., Cognat, V., Holt, D. B., Charpentier, M., Parniske, M., Stougaard, J., and Voinnet, O. 2012. Two microRNAs 
linked to nodule infection and nitrogen-fixing ability in the legume Lotus japonicus. Plant Physiol. 160:2137-2154.

Dénarié, J., Debellé, F., and Promé, J. C. 1996. Rhizobium lipochitooligosaccharide nodulation factors: Signaling molecules mediating recognition and morphogenesis. Annu. Rev. Biochem. 65:503-535.

Devers, E. A., Branscheid, A., May, P., and Krajinski, F. 2011. Stars and symbiosis: microRNA- and microRNA*-mediated transcript cleavage involved in arbuscular mycorrhizal symbiosis. Plant Physiol. 156: 1990-2010.

D’haeseleer, K., Den Herder, G., Laffont, C., Plet, J., Mortier, V., LelandaisBrière, C., De Bodt, S., De Keyser, A., Crespi, M., Holsters, M., Frugier F., and Goormachtig, S. 2011. Transcriptional and post-transcriptional regulation of a NAC1 transcription factor in Medicago truncatula roots. New Phytol. 191:647-661.

Ei-D, A. M. S. E., Salama, A., and Wareing, P. F. 1979. Effects of mineralnutrition on endogenous cytokinins in plants of sunflower (Helianthusannuus L). J. Exp. Bot. 30:971-981.

Etemadi, M., Gutjahr, C., Couzigou, J. M., Zouine, M., Lauressergues, D., Timmers, A., Audran, C., Bouzayen, M., Bécard, G., Combier, J. P. 2014. Auxin perception is required for arbuscule development in arbuscular mycorrhizal symbiosis. Plant Physiol. 166:281-292.

Ferguson, B. J., and Mathesius, U. 2014. Phytohormone regulation of legume-rhizobia interactions. J. Chem. Ecol. 40:770-790.

Foo, E. 2013. Auxin influences strigolactones in pea mycorrhizal symbiosis. J. Plant Physiol. 170:523-528.

Formey, D., Sallet, E., Lelandais-Brière, C., Ben, C., Bustos-Sanmamed, P., Niebel, A., Frugier, F., Combier, J. P., Debellé, F., Hartmann, C., Poulain, J., Gavory, F., Wincker, P., Roux, C., Gentzbittel, L., Gouzy, J., and Crespi, M. 2014. The small RNA diversity from Medicago truncatula roots under biotic interactions evidences the environmental plasticity of the miRNAome. Genome Biol. 15:457.

Formey, D., Iñiguez, L. P., Peláez, P., Li, Y. F., Sunkar, R., Sánchez, F., Reyes, J. L., and Hernández, G. 2015. Genome-wide identification of the Phaseolus vulgaris sRNAome using small RNA and degradome sequencing. BMC Genomics 16:423.

Gobbato, E., Marsh, J. F., Vernié, T., Wang, E., Maillet, F., Kim, J., Miller, J. B., Sun, J., Bano, S. A., Ratet, P., Mysore, K. S., Dénarié, J., Schultze, M., and Oldroyd, G. E. 2012. A GRAS-type transcription factor with a specific function in mycorrhizal signaling. Curr. Biol. 22:2236-2241.

Gobbato, E. 2015. Recent developments in arbuscular mycorrhizal signaling. Curr. Opin. Plant Biol. 26:1-7.

Goettel, W., Liu, Z., Xia, J., Zhang, W., Zhao, P. X., and An, Y. Q. 2014 Systems and evolutionary characterization of microRNAs and their underlying regulatory networks in soybean cotyledons. PLoS One 9: e86153.

Gonzalez-Rizzo, S., Crespi, M., and Frugier, F. 2006. The Medicago truncatula CRE1 cytokinin receptor regulates lateral root development and early symbiotic interaction with Sinorhizobium meliloti. Plant Cell 18:2680-2693.

Gough, C., and Cullimore, J. 2011. Lipo-chitooligosaccharide signaling in endosymbiotic plant-microbe interactions. Mol. Plant-Microbe Interact 24:867-878.

Guilfoyle, T. J., and Hagen, G. 2007. Auxin response factors. Curr. Opin. Plant Biol. 10:453-460.

Gutjahr, C. 2014. Phytohormone signaling in arbuscular mycorhiza development. Curr. Opin. Plant Biol. 20:26-34.

Hanlon, M. T., and Coenen, C. 2011. Genetic evidence for auxin involvement in arbuscular mycorrhiza initiation. New Phytol. 189:701709.

Hardin, S. C., Tang, G. Q., Scholz, A., Holtgraewe, D., Winter, H., and Huber, S. C. 2003. Phosphorylation of sucrose synthase at serine 170: Occurrence and possible role as a signal for proteolysis. Plant J. 35: 588-603.

Heckmann, A. B., Lombardo, F., Miwa, H., Perry, J. A., Bunnewell, S., Parniske, M., Wang, T. L., and Downie, J. A. 2006. Lotus japonicus nodulation requires two GRAS domain regulators, one of which is functionally conserved in a non-legume. Plant Physiol. 142: 1739-1750.

Hirsch, S., Kim, J., Muñoz, A., Heckmann, A. B., Downie, J. A., and Oldroyd, G. E. 2009. GRAS proteins form a DNA binding complex to induce gene expression during nodulation signaling in Medicago truncatula. Plant Cell 21:545-557.

Hirsch, S., and Oldroyd, G. E. 2009. GRAS-domain transcription factors that regulate plant development. Plant Signal. Behav. 4:698-700.

Hofferek, V., Mendrinna, A., Gaude, N., Krajinski, F., and Devers, E. A. 2014. MiR171h restricts root symbioses and shows like its target NSP2 a complex transcriptional regulation in Medicago truncatula. BMC Plant Biol. 14:199.
Holt, D. B., Gupta, V., Meyer, D., Abel, N. B., Andersen, S. U., Stougaard, J., and Markmann, K. 2015. micro RNA 172 (miR172) signals epidermal infection and is expressed in cells primed for bacterial invasion in Lotus japonicus roots and nodules. New Phytol. 208:241-256.

Huijser, P., and Schmid, M. 2011. The control of developmental phase transitions in plants. Development 138:4117-4129.

Jagadeeswaran, G., Zheng, Y., Li, Y. F., Shukla, L. I., Matts, J., Hoyt, P., Macmil, S. L., Wiley, G. B., Roe, B. A., Zhang, W., and Sunkar, R. 2009. Cloning and characterization of small RNAs from Medicago truncatula reveals four novel legume-specific microRNA families. New Phytol. 184:85-98.

Jain, M., Chevala, V. V., and Garg, R. 2014. Genome-wide discovery and differential regulation of conserved and novel microRNAs in chickpea via deep sequencing. J. Exp. Bot. 65:5945-5958.

Kohli, D., Joshi, G., Deokar, A. A., Bhardwaj, A. R., Agarwal, M., KatiyarAgarwal, S., Srinivasan, R., and Jain, P. K. 2014. Identification and characterization of wilt and salt stress-responsive microRNAs in chickpea through high-throughput sequencing. PLoS One 9:e108851.

Jones-Rhoades, M. W. 2012. Conservation and divergence in plant microRNAs. Plant Mol. Biol. 80:3-16.

Kaló, P., Gleason, C., Edwards, A., Marsh, J., Mitra, R. M., Hirsch, S., Jakab, J., Sims, S., Long, S. R., Rogers, J., Kiss, G. B., Downie, J. A., and Oldroyd, G. E. 2005. Nodulation signaling in legumes requires NSP2, a member of the GRAS family of transcriptional regulators. Science 308: 1786-1789.

Khan, G. A., Declerck, M., Sorin, C., Hartmann, C., Crespi, M., and Lelandais-Brière, C. 2011. MicroRNAs as regulators of root development and architecture. Plant Mol. Biol. 77:47-58.

Kouchi, H., Hata, S. 1993. Isolation and characterization of novel nodulin cDNAs representing genes expressed at early stages of soybean nodule development. Mol Gen Genet. 238:106-119.

Kretzschmar, T., Kohlen, W., Sasse, J., Borghi, L., Schlegel, M., Bachelier, J. B., Reinhardt, D., Bours, R., Bouwmeester, H. J., and Martinoia, E. 2012. A petunia ABC protein controls strigolactone-dependent symbiotic signalling and branching. Nature 483:341-344.

Martinez-Romero, E., and Caballero-Mellado, J. 1996. Rhizobium phylogenies and bacterial genetic diversity. Crit. Rev. Plant Sci. 15: 113-140.

Kulcheski, F. R., de Oliveira, L. F., Molina, L. G., Almerão, M. P., Rodrigues, F. A., Marcolino, J., Barbosa, J. F., Stolf-Moreira, R., Nepomuceno, A. L., Marcelino-Guimarães, F. C., Abdelnoor, R. V., Nascimento, L. C., Carazzolle, M. F., Pereira, G. A., and Margis, R. 2011. Identification of novel soybean microRNAs involved in abiotic and biotic stresses. BMC Genomics 12:307.

Laloum, T., De Mita, S., Gamas, P., Baudin, M., and Niebel, A. 2013. CCAAT-box binding transcription factors in plants: Y so many? Trends Plant Sci. 18:157-166.

Laloum, T., Baudin, M., Frances, L., Lepage, A., Billault-Penneteau, B., Cerri, M. R., Ariel, F., Jardinaud, M. F., Gamas, P., de Carvalho-Niebel, F., and Niebel, A. 2014. Two CCAAT-box-binding transcription factors redundantly regulate early steps of the legume-rhizobia endosymbiosis. Plant J. 79:757-768.

Laporte, P., Satiat-Jeunemaître, B., Velasco, I., Csorba, T., Van de Velde, W., Campalans, A., Burgyan, J., Arevalo-Rodriguez, M., and Crespi, M. 2010. A novel RNA-binding peptide regulates the establishment of the Medicago truncatula-Sinorhizobium meliloti nitrogen-fixing symbiosis. Plant J. 62:24-38.

Laporte, P., Lepage, A., Fournier, J., Catrice, O., Moreau, S., Jardinaud, M. F., Mun, J. H., Larrainzar, E., Cook, D. R., Gamas, P., and Niebel, A. 2014. The CCAAT box-binding transcription factor NF-YA1 controls rhizobial infection. J. Exp. Bot. 65:481-494.

Lauressergues, D., Delaux, P. M., Formey, D., Lelandais-Brière, C., Fort, S., Cottaz, S., Bécard, G., Niebel, A., Roux, C., and Combier, J. P. 2012. The microRNA miR171h modulates arbuscular mycorrhizal colonization of Medicago truncatula by targeting NSP2. Plant J. 72:512-522.

Lelandais-Brière, C., Naya, L., Sallet, E., Calenge, F., Frugier, F., Hartmann, C., Gouzy, J., and Crespi, M. 2009. Genome-wide Medicago truncatula small RNA analysis revealed novel microRNAs and isoforms differentially regulated in roots and nodules. Plant Cell 21:2780-2796.

Lévy, J., Bres, C., Geurts, R., Chalhoub, B., Kulikova, O., Duc, G., Journet, E. P., Ané, J. M., Lauber, E., Bisseling, T., Dénarié, J., Rosenberg, C., and Debellé, F. 2004. A putative $\mathrm{Ca}^{2+}$ and calmodulin-dependent protein kinase required for bacterial and fungal symbioses. Science 303:13611364

Li, C., and Zhang, B. 2016. MicroRNAs in control of plant development. J. Cell. Physiol. 231:303-313.

Li, H., Deng, Y., Wu, T., Subramanian, S., and Yu, O. 2010. Misexpression of miR482, miR1512, and miR1515 increases soybean nodulation. Plant Physiol. 153:1759-1770. 
Li, W. X., Oono, Y., Zhu, J., He, X. J., Wu, J. M., Iida, K., Lu, X. Y., Cui, X., Jin, H., and Zhu, J. K. 2008. The Arabidopsis NFYA5 transcription factor is regulated transcriptionally and posttranscriptionally to promote drought resistance. Plant Cell 20:2238-2251.

Li, X., Lei, M., Yan, Z., Wang, Q., Chen, A., Sun, J., Luo, D., and Wang, Y. 2014. The REL3-mediated TAS3 ta-siRNA pathway integrates auxin and ethylene signaling to regulate nodulation in Lotus japonicus. New Phytol. 201:531-544.

Liebminger, E., Hüttner, S., Vavra, U., Fischl, R., Schoberer, J., Grass, J., Blaukopf, C., Seifert, G. J., Altmann, F., Mach, L., and Strasser, R. 2009. Class I alpha-mannosidases are required for $\mathrm{N}$-glycan processing and root development in Arabidopsis thaliana. Plant Cell 21:3850-3867.

Limpens, E., Franken, C., Smit, P., Willemse, J., Bisseling, T., and Geurts, R. 2003. LysM domain receptor kinases regulating rhizobial Nod factorinduced infection. Science 302:630-633.

Liu, W., Kohlen, W., Lillo, A., Op den Camp, R., Ivanov, S., Hartog, M., Limpens, E., Jamil, M., Smaczniak, C., Kaufmann, K., Yang, W. C., Hooiveld, G. J., Charnikhova, T., Bouwmeester, H. J., Bisseling, T., and Geurts, R. 2011. Strigolactone biosynthesis in Medicago truncatula and rice requires the symbiotic GRAS-type transcription factors NSP1 and NSP2. Plant Cell 23:3853-3865.

Madsen, E. B., Madsen, L. H., Radutoiu, S., Olbryt, M., Rakwalska, M., Szczyglowski, K., Sato, S., Kaneko, T., Tabata, S., Sandal, N., and Stougaard, J. 2003. A receptor kinase gene of the LysM type is involved in legume perception of rhizobial signals. Nature 425:637-640.

Mantovani, R., Li, X. Y., Pessara, U., Hooft van Huisjduijnen, R., Benoist, C., and Mathis, D. 1994. Dominant negative analogs of NF-YA. J. Biol. Chem. 269:20340-20346.

Mantovani, R. 1999. The molecular biology of the CCAAT-binding factor NF-Y. Gene 239:15-27.

Maillet, F., Poinsot, V., André, O., Puech-Pagès, V., Haouy, A., Gueunier, M., Cromer, L., Giraudet, D., Formey, D., Niebel, A., Martinez, E. A., Driguez, H., Bécard, G., and Dénarié, J. 2011. Fungal lipochitooligosaccharide symbiotic signals in arbuscular mycorrhiza. Nature 469: 58-63.

Mao, G., Turner, M., Yu, O., and Subramanian, S. 2013. miR393 and miR164 influence indeterminate but not determinate nodule development. Plant Signal. Behav. 8:e26753.

Marsh, J. F., Rakocevic, A., Mitra, R. M., Brocard, L., Sun, J., Eschstruth, A., Long, S. R., Schultze, M., Ratet, P., and Oldroyd, G. E. 2007. Medicago truncatula NIN is essential for rhizobial-independent nodule organogenesis induced by autoactive calcium/calmodulin-dependent protein kinase. Plant Physiol. 144:324-335.

Mathesius, U., Schlaman, H. R., Spaink, H. P., Of Sautter, C., Rolfe, B. G., and Djordjevic, M. A. 1998. Auxin transport inhibition precedes root nodule formation in white clover roots and is regulated by flavonoids and derivatives of chitin oligosaccharides. Plant J. 14:23-34.

Messinese, E., Mun, J. H., Yeun, L. H., Jayaraman, D., Rougé, P., Barre, A., Lougnon, G., Schornack, S., Bono, J. J., Cook, D. R., and Ané, J. M. 2007. A novel nuclear protein interacts with the symbiotic DMI3 calcium- and calmodulin-dependent protein kinase of Medicago truncatula. Mol. Plant-Microbe Interact 20:912-921.

Middleton, P. H., Jakab, J., Penmetsa, R. V., Starker, C. G., Doll, J., Kaló, P., Prabhu, R., Marsh, J. F., Mitra, R. M., Kereszt, A., Dudas, B., VandenBosch, K., Long, S. R., Cook, D. R., Kiss, G. B., and Oldroyd, G. E. 2007. An ERF transcription factor in Medicago truncatula that is essential for Nod factor signal transduction. Plant Cell 19:1221-1234.

Minami, E., Kouchi, H., Cohn, J. R., Ogawa, T., and Stacey, G. 1996. Expression of the early nodulin, ENOD40, in soybean roots in response to various lipo-chitin signal molecules. Plant J. 10:23-32.

Mitra, R. M., Shaw, S. L., and Long, S. R. 2004. Six nonnodulating plant mutants defective for Nod factor-induced transcriptional changes associated with the legume-rhizobia symbiosis. Proc. Natl. Acad. Sci. U.S.A. 101:10217-10222.

Mortier, V., Holsters, M., and Goormachtig, S. 2012. Never too many? How legumes control nodule numbers. Plant Cell Environ. 35:245-258.

Naya, L., Khan, G. A., Sorin, C., Hartmann, C., Crespi, M., and LelandaisBrière, C. 2010. Cleavage of a non-conserved target by a specific miR156 isoform in root apexes of Medicago truncatula. Plant Signal. Behav. 5:328-331.

Ng, J. L., Hassan, S., Truong, T. T., Hocart, C. H., Laffont, C., Frugier, F., and Mathesius, U. 2015. Flavonoids and auxin transport inhibitors rescue symbiotic nodulation in the Medicago truncatula cytokinin perception mutant cre1. Plant Cell 27:2210-2226.

Ni, Z., Hu, Z., Jiang, Q., and Zhang, H. 2013. GmNFYA3, a target gene of miR169, is a positive regulator of plant tolerance to drought stress. Plant Mol. Biol. 82:113-129.

Nova-Franco, B., Íñiguez, L. P., Valdés-López, O., Alvarado-Affantranger, X., Leija, A., Fuentes, S. I., Ramírez, M., Paul, S., Reyes, J. L., Girard, L., and Hernández, G. 2015. The micro-RNA72c-APETALA2-1 node as a key regulator of the common bean-Rhizobium etli nitrogen fixation symbiosis. Plant Physiol. 168:273-291.

Okushima, Y., Overvoorde, P. J., Arima, K., Alonso, J. M., Chan, A., Chang, C., Ecker, J. R., Hughes, B., Lui, A., Nguyen, D., Onodera, C. Quach, H., Smith, A., Yu, G., and Theologis, A. 2005. Functional genomic analysis of the AUXIN RESPONSE FACTOR gene family members in Arabidopsis thaliana: Unique and overlapping functions of $A R F 7$ and ARF19. Plant Cell 17:444-463.

Oldroyd, G. E., and Long, S. R. 2003. Identification and characterization ofNSP2, a gene of Medicago truncatula involved in Nod actor signaling. Plant Physiol. 131:1027-1032.

Oldroyd, G. E. D. 2013. Speak, friend, and enter: Signalling systems that promote beneficial symbiotic associations in plants. Nat. Rev. Microbiol. $11: 252-263$.

Overvoorde, P. J., Okushima, Y., Alonso, J. M., Chan, A., Chang, C., Ecker, J. R., Hughes, B., Liu, A., Onodera, C., Quach, H., Smith, A., Yu, G. and Theologis, A. 2005. Functional genomic analysis of the AUXIN/ INDOLE-3-ACETIC ACID gene family members in Arabidopsis thaliana. Plant Cell 17:3282-3300.

Pacios-Bras, C., Schlaman, H. R., Boot, K., Admiraal, P., Langerak, J. M., Stougaard, J., and Spaink, H. P. 2003. Auxin distribution in Lotus japonicus during root nodule development. Plant Mol. Biol. 52:11691180.

Parent, J. S., Bouteiller, N., Elmayan, T., and Vaucheret, H. 2015 Respective contributions of Arabidopsis DCL2 and DCL4 to RNA silencing. Plant J. 81:223-232.

Parry, G., Calderon-Villalobos, L. I., Prigge, M., Peret, B., Dharmasiri, S. Itoh, H., Lechner, E., Gray, W. M., Bennett, M., and Estelle, M. 2009. Complex regulation of the TIR1/AFB family of auxin receptors. Proc. Natl. Acad. Sci. U.S.A. 106:22540-22545.

Patriarca, E. J., Tatè, R., Ferraioli, S., and Iaccarino, M. 2004 Organogenesis of legume root nodules. Int. Rev. Cytol. 234:201-262.

Plet, J., Wasson, A., Ariel, F., Le Signor, C., Baker, D., Mathesius, U., Crespi, M., and Frugier, F. 2011. MtCRE1-dependent cytokinin signaling integrates bacterial and plant cues to coordinate symbiotic nodule organogenesis in Medicago truncatula. Plant J. 65:622-633.

Prayitno, J., Rolfe, B. G., and Mathesius, U. 2006. The ethylene-insensitive sickle mutant of Medicago truncatula shows altered auxin transport regulation during nodulation. Plant Physiol. 142:168-180.

Redmond, J. W., Batley, M., Djordjevic, M. A., Innes, R. W., Kuempel, P. L., and Rolfe, B. G. 1986. Flavones induce expression of nodulation genes in Rhizobium. Nature 323:632-635.

Reynoso, M. A., Blanco, F. A., Bailey-Serres, J., Crespi, M., and Zanetti, M. E. 2013. Selective recruitment of mRNAs and miRNAs to polyribosomes in response to rhizobia infection in Medicago truncatula. Plant J. 73:289-301.

Rich, M. K., Schorderet, M., Bapaume, L., Falquet, L., Morel, P., Vandenbussche, M., and Reinhardt, D. 2015. The petunia GRAS transcription factor ATA/RAM1 regulates symbiotic gene expression and fungal morphogenesis in arbuscular mycorrhiza. Plant Physiol. 168:788-797.

Röhrig, H., Schmidt, J., Miklashevichs, E., Schell, J., and John, M. 2002. Soybean ENOD40 encodes two peptides that bind to sucrose synthase. Proc. Natl. Acad. Sci. U.S.A. 99:1915-1920.

Röhrig, H., John, M., and Schmidt, J. 2004. Modification of soybean sucrose synthase by S-thiolation with ENOD40 peptide A. Biochem. Biophys. Res. Commun. 325:864-870.

Rubio-Somoza, I., and Weigel, D. 2011. MicroRNA networks and developmental plasticity in plants. Trends Plant Sci. 16:258-264.

Schauser, L., Roussis, A., Stiller, J., and Stougaard, J. 1999. A plant regulator controlling development of symbiotic root nodules. Nature 402:191-195.

Searle, I. R., Men, A. E., Laniya, T. S., Buzas, D. M., Iturbe-Ormaetxe, I., Carroll, B. J., and Gresshoff, P. M. 2003. Long-distance signaling in nodulation directed by a CLAVATA1-like receptor kinase. Science 299: 109-112.

Si-Ammour, A., Windels, D., Arn-Bouldoires, E., Kutter, C., Ailhas, J., Meins, F. Jr., and Vazquez, F. 2011. miR393 and secondary siRNAs regulate expression of the TIR1/AFB2 auxin receptor clade and auxinrelated development of Arabidopsis leaves. Plant Physiol. 157:683-691.

Simon, S. A., Meyers, B. C., and Sherrier, D. J. 2009. MicroRNAs in the rhizobia legume symbiosis. Plant Physiol. 151:1002-1008.

Smit, P., Raedts, J., Portyanko, V., Debellé, F., Gough, C., Bisseling, T., and Geurts, R. 2005. NSP1 of the GRAS protein family is essential for rhizobial Nod factor-induced transcription. Science 308:1789-1791.

Smith, S. E., and Gianinazzi-Pearson, V. 1988. Physiological interactions between symbionts in vesicular-arbuscular mycorrhizal plants. Annu. Rev. Plant Physiol. Plant Mol. Biol. 39:221-244. 
Song, Q. X., Liu, Y. F., Hu, X. Y., Zhang, W. K., Ma, B., Chen, S. Y., and Zhang, J. S. 2011. Identification of miRNAs and their target genes in developing soybean seeds by deep sequencing. BMC Plant Biol. 11:5.

Sorin, C., Declerck, M., Christ, A., Blein, T., Ma, L., Lelandais-Brière, C., Njo, M. F., Beeckman, T., Crespi, M., and Hartmann, C. 2014. A miR169 isoform regulates specific NF-YA targets and root architecture in Arabidopsis. New Phytol. 202:1197-1211.

Soyano, T., Kouchi, H., Hirota, A., and Hayashi, M. 2013. Nodule inception directly targets $N F-Y$ subunit genes to regulate essential processes of root nodule development in Lotus japonicus. PLoS Genet. 9:e1003352.

Strack, D., Fester, T., Hause, B., Schliemann, W., and Walter, M. H. 2003. Arbuscular mycorrhiza: Biological, chemical, and molecular aspects. J. Chem. Ecol. 29:1955-1979.

Stracke, S., Kistner, C., Yoshida, S., Mulder, L., Sato, S., Kaneko, T., Tabata, S., Sandal, N., Stougaard, J., Szczyglowski, K., and Parniske, M. 2002. A plant receptor-like kinase required for both bacterial and fungal symbiosis. Nature 417:959-962.

Subramanian, S., Fu, Y., Sunkar, R., Barbazuk, W. B., Zhu, J. K., and Yu, O. 2008. Novel and nodulation-regulated microRNAs in soybean roots. BMC Genomics 9:160.

Suzaki, T., Yano, K., Ito, M., Umehara, Y., Suganuma, N., and Kawaguchi, M. 2012. Positive and negative regulation of cortical cell division during root nodule development in Lotus japonicus is accompanied by auxin response. Development 139:3997-4006.

Suzaki, T., Ito, M., and Kawaguchi, M. 2013. Genetic basis of cytokinin and auxin functions during root nodule development. Front. Plant Sci. 4:42.

Szittya, G., Moxon, S., Santos, D. M., Jing, R., Fevereiro, M. P., Moulton, V., and Dalmay, T. 2008. High-throughput sequencing of Medicago truncatula short RNAs identifies eight new miRNA families. BMC Genomics 9:593.

Takeda, N., Tsuzuki, S., Suzaki, T., Parniske, M., and Kawaguchi, M. 2013. CERBERUS and NSP1 of Lotus japonicus are common symbiosis genes that modulate arbuscular mycorrhiza development. Plant Cell Physiol. 54:1711-1723.

Thorneley, R. N. F. 1992. Nitrogen fixation-new light on nitrogenase. Nature 360:532-533.

Tirichine, L., James, E. K., Sandal, N., and Stougaard, J. 2006. Spontaneous root-nodule formation in the model legume Lotus japonicus: A novel class of mutants nodulates in the absence of rhizobia. Mol. PlantMicrobe Interact 19:373-382.

Tirichine, L., Sandal, N., Madsen, L. H., Radutoiu, S., Albrektsen, A. S., Sato, S., Asamizu, E., Tabata, S., and Stougaard, J. 2007. A gain-offunction mutation in a cytokinin receptor triggers spontaneous root nodule organogenesis. Science 315:104-107.

Turner, M., Nizampatnam, N. R., Baron, M., Coppin, S., Damodaran, S., Adhikari, S., Arunachalam, S. P., Yu, O., and Subramanian, S. 2013. Ectopic expression of miR160 results in auxin hypersensitivity, cytokinin hyposensitivity, and inhibition of symbiotic nodule development in soybean. Plant Physiol. 162:2042-2055

Vazquez, F., Legrand, S., and Windels, D. 2010. The biosynthetic pathways and biological scopes of plant small RNAs. Trends Plant Sci. 15:337-345.

Vernié, T., Moreau, S., de Billy, F., Plet, J., Combier, J. P., Rogers, C., Oldroyd, G., Frugier, F., Niebel, A., and Gamas, P. 2008. EFD Is an ERF transcription factor involved in the control of nodule number and differentiation in Medicago truncatula. Plant Cell 20:2696-2713.

Vidal, E. A., Araus, V., Lu, C., Parry, G., Green, P. J., Coruzzi, G. M., and Gutiérrez, R. A. 2010. Nitrate-responsive miR393/AFB3 regulatory module controls root system architecture in Arabidopsis thaliana. Proc. Natl. Acad. Sci. U.S.A. 107:4477-4482.

Wang, Y., Li, P., Cao, X., Wang, X., Zhang, A., and Li, X. 2009. Identification and expression analysis of miRNAs from nitrogen-fixing soybean nodules. Biochem. Biophys. Res. Commun. 378:799-803.

Wang, E., Schornack, S., Marsh, J. F., Gobbato, E., Schwessinger, B., Eastmond, P., Schultze, M., Kamoun, S., and Oldroyd, G. E. 2012. A common signaling process that promotes mycorrhizal and oomycete colonization of plants. Curr. Biol. 22:2242-2246.

Wang, Y., Li, K., Chen, L., Zou, Y., Liu, H., Tian, Y., Li, D., Wang, R., Zhao, F., Ferguson, B. J., Gresshoff, P. M., and Li, X. 2015a. MicroRNA167-directed regulation of the auxin response factors GmARF8a and GmARF8b is required for soybean nodulation and lateral root development. Plant Physiol. 168:984-999.

Wang, Y., Wang, L., Zou, Y., Chen, L., Cai, Z., Zhang, S., Zhao, F., Tian, Y., Jiang, Q., Ferguson, B. J., Gresshoff, P. M., and Li, X. 2014. Soybean miR172c targets the repressive AP2 transcription factor NNC1 to activate ENOD40 expression and regulate nodule initiation. Plant Cell 26: 4782-4801.
Wang, Y., Wang, Z., Amyot, L., Tian, L., Xu, Z., Gruber, M. Y., and Hannoufa, A. 2015b. Ectopic expression of miR156 represses nodulation and causes morphological and developmental changes in Lotus japonicus. Mol. Genet. Genomics 290:471-484.

Windels, D., Bielewicz, D., Ebneter, M., Jarmolowski, A., SzweykowskaKulinska, Z., Vazquez, F. 2014. miR393 is required for production of proper auxin signalling outputs. PLoS One. 9:e95972.

Wu, G., Park, M. Y., Conway, S. R., Wang, J. W., Weigel, D., and Poethig, R. S. 2009. The sequential action of miR156 and miR172 regulates developmental timing in Arabidopsis. Cell 138:750-759.

Xie, Q., Frugis, G., Colgan, D., and Chua, N. H. 2000. Arabidopsis NAC1 transduces auxin signal downstream of TIR1 to promote lateral root development. Genes Dev. 14:3024-3036.

Xue, L., Cui, H., Buer, B., Vijayakumar, V., Delaux, P. M., Junkermann, S., and Bucher, M. 2015. Network of GRAS transcription factors involved in the control of arbuscule development in Lotus japonicus. Plant Physiol. 167:854-871.

Yan, J., Cai, X., Luo, J., Sato, S., Jiang, Q., Yang, J., Cao, X., Hu, X., Tabata, S., Gresshoff, P. M., and Luo, D. 2010. The REDUCED LEAFLET genes encode key components of the trans-acting small interfering RNA pathway and regulate compound leaf and flower development in Lotus japonicus. Plant Physiol. 152:797-807.

Yan, Z., Hossain, M. S., Arikit, S., Valdés-López, O., Zhai, J., Wang, J., Libault, M., Ji, T., Qiu, L., Meyers, B. C., and Stacey, G. 2015a. Identification of microRNAs and their mRNA targets during soybean nodule development: Functional analysis of the role of miR393j-3p in soybean nodulation. New Phytol. 207:748-759.

Yan, Z., Hossain, M. S., Valdés-López, O., Hoang, N. T., Zhai, J., Wang, J., Libault, M., Brechenmacher, L., Findley, S., Joshi, T., Qiu, L., Sherrier, D. J., Ji, T., Meyers, B. C., Xu, D., and Stacey, G. 2015b. Identification and functional characterization of soybean root hair microRNAs expressed in response to Bradyrhizobium japonicum infection. Plant Biotechnol. J. 14:10.1111/pbi.12387.

Yan, Z., Hossain, M. S., Wang, J., Valdés-López, O., Liang, Y., Libault, M., Qiu, L., and Stacey, G. 2013. miR172 regulates soybean nodulation. Mol. Plant-Microbe Interact 26:1371-1377.

Yano, K., Yoshida, S., Müller, J., Singh, S., Banba, M., Vickers, K., Markmann, K., White, C., Schuller, B., Sato, S., Asamizu, E., Tabata, S., Murooka, Y., Perry, J., Wang, T. L., Kawaguchi, M., Imaizumi-Anraku, H., Hayashi, M., and Parniske, M. 2008. CYCLOPS, a mediator of symbiotic intracellular accommodation. Proc. Natl. Acad. Sci. U.S.A. 105:20540-20545.

Yoshida, S., Kameoka, H., Tempo, M., Akiyama, K., Umehara, M., Yamaguchi, S., Hayashi, H., Kyozuka, J., and Shirasu, K. 2012. The D3 F-box protein is a key component in host strigolactone responses essential for arbuscular mycorrhizal symbiosis. New Phytol. 196: 1208-1216.

Yu, N., Niu, Q. W., Ng, K. H., and Chua, N. H. 2015. The role of miR156/SPLs modules in Arabidopsis lateral root development. Plant J. 83:673-685.

Zanetti, M. E., Blanco, F. A., Beker, M. P., Battaglia, M., and Aguilar, O. M. 2010. A C subunit of the plant nuclear factor NF-Y required for rhizobial infection and nodule development affects partner selection in the common bean-Rhizobium etli symbiosis. Plant Cell 22:4142-4157.

Zemzoumi, K., Frontini, M., Bellorini, M., and Mantovani, R. 1999. NF-Y histone fold $\alpha 1$ helices help impart CCAAT specificity. J. Mol. Biol. 286: 327-337.

Zhai, J., Jeong, D. H., De Paoli, E., Park, S., Rosen, B. D., Li, Y., González, A. J., Yan, Z., Kitto, S. L., Grusak, M. A., Jackson, S. A., Stacey, G., Cook, D. R., Green, P. J., Sherrier, D. J., and Meyers, B. C. 2011. MicroRNAs as master regulators of the plant $N B-L R R$ defense gene family via the production of phased, trans-acting siRNAs. Genes Dev. 25:2540-2553.

Zhao, C. Z., Xia, H., Frazier, T. P., Yao, Y. Y., Bi, Y. P., Li, A. Q., Li, M. J., Li, C. S., Zhang, B. H., and Wang, X. J. 2010. Deep sequencing identifies novel and conserved microRNAs in peanuts (Arachis hypogaea L.). BMC Plant Biol. 10:3.

Zhao, M., Ding, H., Zhu, J. K., Zhang, F., and Li, W. X. 2011. Involvement of miR169 in the nitrogen-starvation responses in Arabidopsis. New Phytol. 190:906-915.

\section{AUTHOR-RECOMMENDED INTERNET RESOURCE}

miRBAse, the miRNA database: www.mirbase.org 